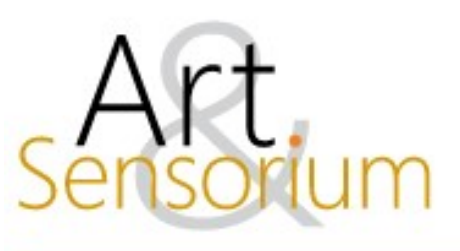

\title{
A CRÍTICA DE ARTE DE GUILLAUMe APOLLINAIRE NAS PÁGINAS DA REVISTA SOIRÉES DE PARIS
}

\author{
https://doi.org/10.33871/23580437.2021.8.1.271-281
}

Conrado Augusto Barbosa Fogagnoli ${ }^{1}$

\begin{abstract}
Resumo: Neste artigo trato da crítica artística de Guillaume Apollinaire nas páginas da revista, por ele dirigida, Soirées de Paris. Para tanto, exponho o quadro geral em que se organiza a publicação apresentando seus principais colaboradores. Demonstro como a revista se organizou em sua primeira fase, dirigida por André Billy, para posteriormente evidenciar a mudança operada a partir da direção de Apollinaire. Apresento as discussões artísticas propostas pelo autor bem como a sua preocupação em divulgar a arte de seus companheiros pintores.
\end{abstract}

Palavras-chave: Guillaume Apollinaire; crítica de artes; pintura francesa.

\section{THE GUILLAUME APOLLINAIRE ART CRITICISM ON THE PAGES OF SOIRÉES DE PARIS MAGAZINE}

Abstract: In this article I deal with Guillaume Apollinaire's artistic criticism in the pages of the magazine, directed by him, Soirées de Paris. To this end, I present the general framework in which the publication is organized, presenting its main collaborators. I demonstrate how the magazine was organized in its first phase, directed by André Billy, to later show the change made by Apollinaire's direction. I present the artistic discussions proposed by the author as well as his concern in promoting the art of his fellow painters.

Keywords: Guillaume Apollinaire; art criticism; French painting.

\section{LA CRÍTICA DE ARTE DE GUILLAUME APOLLINAIRE EN LAS PÁGINAS DE LA REVISTA SOIRÉES DE PARIS}

Resumen: En este artículo me ocupo de la crítica artística de Guillaume Apollinaire en las páginas de la revista, dirigida por él, Soirées de Paris. Para ello, presento el marco general en el que se organiza la publicación, presentando a sus principales colaboradores. Demuestro cómo se organizó la revista en su primera fase, dirigida por André Billy, para luego mostrar el cambio realizado por la dirección de Apollinaire. Les presento las discusiones artísticas propuestas por el autor así como su preocupación por promover el arte de sus compañeros pintores.

Palabras clave: Guillaume Apollinaire; crítica de arte; Pintura francesa.

\footnotetext{
${ }^{1}$ Doutor em Teoria Literária e Literatura Comparada pela Universidade de São Paulo. Atualmente é pesquisador de pósdoutorado do Departamento de Teoria Literária e Literatura Comparada da Universidade de São Paulo - São Paulo, Brasil. Email: conrado.fogagnoli@usp.br
} 
No dia 15 de fevereiro de 1912 publica-se o primeiro número da revista literária e artística Les Soirées de Paris. Inicialmente mais literária que artística, a revista é dirigida por André Billy em sua primeira fase, após a qual, iniciada a segunda fase, em julho de 1913, será dirigida por Guillaume Apollinaire que se empenha desde os primeiros números publicados em realizar uma verdadeira campanha em favor da pintura moderna, além de publicar na mesma revista alguns de seus poemas que ulteriormente ingressarão na lista dos mais importantes poemas produzidos em língua francesa na primeira metade do século $\mathrm{XX}^{2}$.

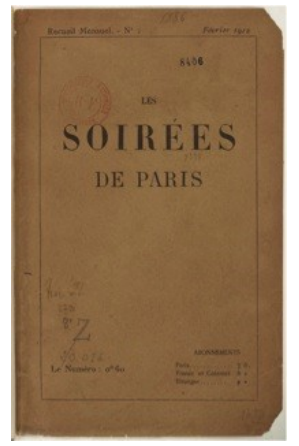

Figura 1 - Capa da $1^{\mathrm{a}}$ edição de Les Soirées de Paris Fevereiro de 1912 Fonte: Gallica - Bibliotèque Nationale de France

Sobre o processo de fundação de Les Soirées de Paris, o primeiro editor da revista lembra que foi sua a iniciativa de organizar a publicação. Segundo Billy (1966, p. 70 e ss.), o final do ano de 1911 havia abalado Apollinaire em razão de sua injustificada detenção, ocorrida entre os dias 7 e 12 de setembro, sob acusão de receptação de duas estatuetas roubadas, anos antes, do Museu do Louvre ${ }^{3}$. Além dessa acusação, menor, o autor foi também indiciado por suspeita de ser o autor do roubo de La Gioconda, de Leonardo Da Vinci, obra pertencente ao mesmo museu.

Billy escreve que a sua finalidade era a de apenas fazer com que o poeta voltasse à sua atividade periodística $^{4}$, exercida desde os primeiros anos do século XX e bruscamente interrompida pelo referido episódio. Com este propósito, procurou então três dentre os melhores amigos de Apollinaire para lhes comunicar a ideia da organização de uma revista nos moldes das que circulavam naqueles anos de 1910 em Paris. Proposta aceita, restava a ele, André Tudesq, André Salmon e René Dupuy doravante René Dalize - apresentá-la a Apollinaire.

Sem mencionar o verdadeiro propósito que os moviam, os quatro companheiros procuram o poeta e expõem sobre o novo projeto, assegurando a Apollinaire toda a liberdade para promover um verdadeiro "combate em favor da pintura moderna" (BILLY, 1966, p. 71) ${ }^{5}$. André Billy se encarregaria de ilustrar as "Cenas da Vida Literária em Paris", André Tudesq, que segundo Billy se interessava mais pelo "exotismo, pelo extremo oriente e pelo ópio" (1966, p. 74), contribuiria com poemas e textos diversos, atuando inclusive como correspondente internacional das Soirées de Paris

\footnotetext{
${ }^{2}$ Além publicação dos textos sobre pintura e dos poemas, ao longo da trajetória da revista Apollinaire colabora com textos muito variados, como os de divulgação de exposições, de salões de arte, de espetáculos teatrais e musicais e comentários de livros recém publicados ou recém traduzidos.

${ }^{3} \mathrm{O}$ episódio é relatado e explicado pelo próprio Apollinaire em carta dirigida a Madeleine Pagès, datada de 30 de junho de 1915 (APOLLINAIRE, 1952, p. 70-71).

${ }^{4}$ É importante destacar que, apesar da afirmação feita por André Billy, Apollinaire não deixa de publicar seus artigos na coluna por ele assinada, "La Vie Artistique", no periódico L'Intransigeant, com o qual colaborava desde o ano de 1910. Ainda que tenha suspendido suas atividades por alguns dias, posteriormente à sua detenção o poeta retoma o trabalho quase com a mesma frequência.

${ }^{5}$ Sabe-se que desde os primeiros textos publicados em jornais parisienses Apollinaire já evidenciava interesse pelo trabalho dos "jeunes peintres", modo como se referia aos representantes da moderna pintura produzida em Paris nos primeiros anos do século XX. Basta lembrar que, entre os primeiros textos publicados pelo poeta, isto em 1905, estão os que ele trata da pintura de Picasso, pintor que havia se estabelecido na capital francesa a pouco mais de um ano, em 1904.
} 
na cobertura da Guerra dos Balkans em 1912. Salmon colaboraria em apenas dois números e René Dalize, assim como Tudesq, também colaboraria com textos bastante distintos, cujos títulos sugerem uma ideia: "Literatura dos Intoxicados", "Variações sobre o Canibalismo", "Apelo aos Bárbaros", "Sob um Vulcão". Apollinaire, além dos poemas que posteriormente o consagrariam, como Pont Mirabeau, Lundi Rue Christine ou Zone, publica, sobretudo, textos sobre a nova pintura que então conquistava espaço nas novas galerias e nos Salões de pintura organizados em Paris.

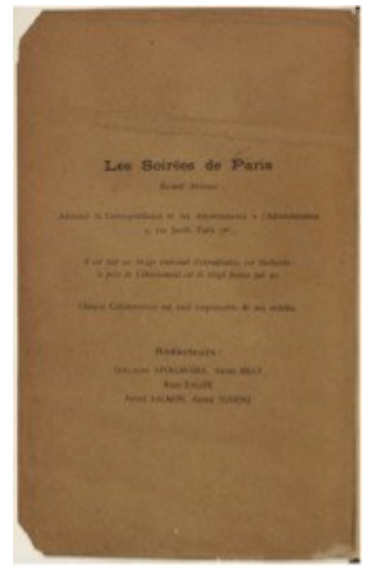

Figura 2 - Folha de rosto da primeira edição de Les Soirées de Paris

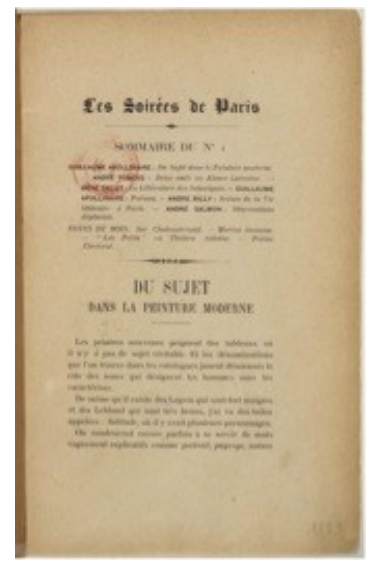

Figura 3 - Sumário da mesma edição e, abaixo, o primeiro texto de Apollinaire nela publicado

Fonte: Gallica - Bibliotèque Nationale de France

O título dado à publicação é também uma sugestão de André Billy que, entre outras Soirées ${ }^{6}$, como as de Médan, de Saint-Pétersbourg e de Neuilly, sugere a de Paris. É ele ainda quem se ocupa de encontrar um impressor "à bon marché" e que cuida de todos os demais detalhes relativos à publicação, detalhes estes que, segundo Billy, nesta época não interessam a Apollinaire.

Sempre segundo Billy, René Dalize é o único entre os companheiros de Apollinaire que se compromete seriamente com o projeto, já que na visão do autor, para ele e para os demais colaboradores tratava-se de um simples divertimento juvenil. Tal comprometimento leva Dalize a assumir, inclusive, a tarefa mais árdua, concernente à administração, e é ele mesmo quem redige o contrato que deve ser assinado por todos os colaboradores das Soirées. Neste documento, Dalize prescreve que, em caso de falta de contribuição, com textos, e principalmente com os 25 francos mensais exigidos para a manutenção da edição dos números da revista, o colaborador será afastado da publicação. Pouco tempo depois, reunidos no Café de Flore, Billy apresenta a primeira prova da revista, aceita, não sem discussões, por todos os membros.

O relato de Billy permite entender que a Soirées não era uma exceção no contexto das revistas que se publicavam naqueles anos em Paris e, como observa Noëmi Blumenkranz-Onimus (1971, p. 1097 1104), muitas eram as publicações circulantes entre os anos de 1912 e 1914 que se dedicavam à defesa das artes modernas - incluindo-se nelas as letras. Objetivamente, conforme a mesma autora, o intuito destas publicações era o de estabelecer um contraponto com outras, mais conservadoras, como a exemplo da Gazette de Beaux-Arts que, circulante desde meados do século XIX, detinha certa hegemonia em relação aos demais periódicos dedicados às artes e às letras na França e, ainda naqueles anos de 1912, defendia ideias de arte presas ao já passado século XIX.

\footnotetext{
${ }^{6}$ Les Soirées de Médan foi o título dado a uma antologia composta por textos de Émile Zola, Guy de Maupassant, JorisKarl Huysmann, entre outros, publicada em abril de 1880. Les Soirées de Saint-Pétersbourg, título de uma obra de Joseph de Maistre, publicada em 1821. Les Soirées de Neuilly título da antologia teatral publicada em 1827 por Hygin-Auguste Cavé - também conhecido pelo pseudônimo M. de Fongeray - com a colaboração de Adolphe Dittmer
} 
Entre as publicações que se destacam por volta dos anos em que a Soirées começa a ser publicada, encontram-se revistas como L'Essor, Cahiers de l'Art Moderne ou, ainda, Poème et Drame, revista dirigida por Henri-Martin Barzun para a qual Apollinaire contribui. Movidas pelo mesmo empenho de defesa da nova arte que se afirma nestes anos, todas estas revistas dão destaque ao moderno - tanto em arte literária quanto em artes plásticas - e embora Les Soirées de Paris possa ser incluída neste mesmo rol de publicações, ela se distingue das demais especialmente pelas ideias, pintores e pinturas defendidos e divulgados por Apollinaire - o que nem sempre é aceito com unanimidade pelos colaboradores do periódico.

É o que se nota, por exemplo, desde o primeiro artigo publicado por Apollinaire, que provoca a indignação, segundo escrevem, de seu companheiro de revista René Dalize. Como destaca André Parinaud (1994), certamente apoiado em Pierre-Marcel Adéma (1952, p. 146-147), Dalize teria reagido contra a publicação do artigo "Du Sujet dans la Peinture Moderne" (1912) ${ }^{7}$, afirmando que o que nele expunha Apollinaire era "uma bobagem, um absurdo [...]. Você [teria dito Dalize] vai nos afundar com o seu cubismo! A Soirées de Paris não foi criada para defender pintores ignorantes e pretensiosos como os que você se relaciona [...] e que, com exceção de quatro ou cinco, não possuem nenhum talento" (PARINAUD, 1994, p. 288). É preciso sublinhar que, entre os pintores "ignorantes e pretensiosos", na visão de Dalize, estavam aqueles que se destacariam como os mais importantes artistas da pintura moderna francesa do século XX, como Pablo Picasso, Georges Braque, Robert Delaunay, André Derain, Henri Matisse, entre outros.

Neste artigo, que inclusive abre o primeiro número de Soirées de Paris, Apollinaire enfatiza que para a pintura da época o tema, ou o assunto do quadro, tinha pouca, ou quase nenhuma importância ${ }^{8}$ especialmente para o trabalho dos "jovens pintores", como os destacados acima, cujas obras o poeta divulga na revista. Além disso, propõe que a própria ideia de gênero pictórico já não serve mais a estes pintores: "Algumas vezes admitimos ainda o emprego de palavras vagamente explicativas, como retrato, paisagem, natureza morta; mas muitos dos jovens pintores empregam apenas o termo mais genérico de pintura".

A inobservância destes gêneros, ou melhor, a deliberada recusa deles, constituía um aspecto característico da pintura produzida no período: não se importando com estes, ou a eles dando pouca importância, os artistas fixavam-se em questões estritamente plásticas, tais como o trabalho com as linhas - como no caso do uso que delas fazem os chamados pintores cubistas -, ou com a cor - como no caso das aplicações que dela fazem os fauves - para mencionar apenas duas dentre as distintas especulações que davam outras direções para a produção pictórica de alguns artistas da época. Como lembra Apollinaire (1913) em um de seus textos publicados nas Soirées de Paris, naquele momento era necessário reduzir a pintura "a seus estritos elementos"9.

Este esforço em se ocupar daquilo que é considerado estritamente relativo à atividade plástica é exemplificado não apenas pelas próprias obras exibidas na época mas também por depoimentos de alguns dos artistas que as produziram. André Derain - cujas obras são reproduzidas por iniciativa de

\footnotetext{
${ }^{7}$ Observe-se que este artigo será reaproveitado na composição de Les Peintres Cubistes. Méditations Esthétiques, que será publicado um ano mais tarde, em março de 1913.

${ }^{8}$ Esta mesma discussão já havia sido posta em circulação por Apollinaire em dois outros artigos publicados no mesmo mês em que as Soirées lança o seu primeiro número. No dia 7 de fevereiro, Apollinaire publica no periódico L'Intransigeant um artigo intitulado Les Peintres Futuristes Italiens, no qual ataca os pintores ligados ao grupo de Marinetti, afirmando sobre estes a sua excessiva - quase exclusiva - preocupação com o "tema" de suas telas. Segundo Apollinaire, os pintores de vanguarda não deveriam se preocupar com "qualquer tema" pois esta preocupação era o que caracterizava, segundo ele, a pintura "pompier", já desgastada e desprezada por muitos artistas da época. Dois dias depois, em 9 do mesmo mês, Apollinaire volta ao assunto em artigo publicado no Le Petit Bleu, do qual era também colaborador, enfatizando a pouca importância dada ao tema pelos "jeunes peintres" franceses e destacando suas preocupações "puramente plásticas"

${ }^{9}$ Note-se que, como "Le Sujet dans la Peinture Moderne", este texto também será reaproveitado no volume publicado por Apollinaire no mesmo ano de 1913, Les Peintres Cubistes. Méditations Esthétiques, editado por Eugène Figuière.
} 
Apollianire na revista - afirmava a este respeito que "a cada vez que manejamos o pincel é necessário que nos coloquemos, de uma só vez, todos os problemas da pintura" (DERAIN apud PARINAUD, 1994, p. 146). Maurice Denis, um pouco mais velho que este, lembrava aos espectadores que um quadro "antes de ser um cavalo de batalha, uma mulher ou qualquer outro assunto, é uma superfície plana, recoberta de cores e composto em uma certa ordem" (VENTURI, 1969, p. 279). Em sentido semelhante a estas posições em relação à pintura, Apollinaire escreve já em 1912, no mesmo artigo no qual discute a questão dos temas, que para a pintura praticada naqueles anos "a verossimilhança não tem qualquer importância, pois o artista sacrifica tudo em favor da composição de seu quadro. $\mathrm{O}$ tema [que era de importância para uma parcela considerável pintores do século anterior, por exemplo] não importa mais ou se ele importa, importa pouco" (APOLLINAIRE, 1912, p.2).

Esta nova prática pictórica será entendida por Apollinaire como "pintura pura", expressão utilizada por ele para denominar a nova arte que alguns artistas estavam empenhados em criar e que, ora comentados, ora tendo suas obras reproduzidas, estarão sempre presentes na curta, mas intensa trajetória da Soirées de Paris. Segundo o poeta: "Nos encaminhamos em direção a uma arte inteiramente nova, que será na pintura [...], o que a música é em relação à literatura. Será a pintura pura, da mesma maneira como a música e a literatura pura" (APOLLINAIRE, 1912, p.2).

A aproximação entre a música e a literatura, corrente na França desde o século XIX ${ }^{10}$, é explicitada por Apollinaire ao argumentar que, do mesmo modo como a música extrai seus sons de combinações e articulações de notas musicais - ou seja, de elementos estritamente relativos ao universo musical e não extraídos do universo natural - a literatura se faz dos elementos que compõem a linguagem humana, e não do que lhe é externa. Consequentemente, a pintura, na visão do poeta, deveria operar do mesmo modo ${ }^{11}$, atendo-se, portanto, aos elementos específicos do trabalho pictórico: o desenho, a cor, a distribuição de luzes, a composição, sempre de modo distinto do que havia sido feito até então. Neste sentido, os pintores deveriam aplicar toda sua atenção a estes elementos e proceder como Pablo Picasso, pintor que, segundo Apollinaire (1912, p.4), "estuda seu objeto como um cirurgião disseca um cadáver".

A preocupação com a chamada "pintura pura" absorve a reflexão de Apollinaire nestes anos ${ }^{12}$. Prova disso são os demais textos que o poeta publica na mesma Soirées de Paris, nos quais sempre retorna ao tema, como a exemplo do artigo publicado no número seguinte da revista: "La Peinture Nouvelle" (1912a). Neste texto, Apollinaire volta a atacar a mesma questão, e conduzindo novamente sua reflexão em direção à "pintura pura" escreve: "Critica-se os pintores novos por suas preocupações geométricas. No entanto as figuras geométricas são o essencial do desenho. A geometria, ciência que tem por objeto a extensão, sua medida e suas relações, foi todo o tempo a regra mesma da pintura" (1912a, p. 89). Destaque-se que, com isso, Apollinaire não propõe equivalência entre a atividade de pintores e de geômetras, o que se torna claro ao considerarmos uma analogia, proposta por ele, segundo a qual a geometria estaria para as artes plásticas assim como a gramática estaria para a literatura, ou seja, um meio de operar a linguagem.

\footnotetext{
${ }^{10}$ John Golding escreve que uma das idéias recorrentes no século XIX foi "a de que a música era a arte nobre por excelência, em razão de seu caracter não-imitativo e as aproximações entre música e literatura se fizeram cada vez mais numerosas através de todo o período da pintura cubista" (1965, p. 41).

${ }^{11}$ Note-se que, se neste texto o paralelo entre a música e a pintura visa a aproximação das duas artes, em outro Apollinaire propõe o mesmo paralelo para destacar o que as distingue. Em artigo sobre o primeiro Salão de Outono de Berlin de 1913, publicado no $\mathrm{n}^{\mathrm{o}} 19$ da revista, o poeta distingue música e pintura propondo que a primeira é uma arte "sucessiva" e a segunda uma arte "simultânea" pois, como ele considera, na pintura "tudo se apresenta ao mesmo tempo", ao passo que na música "tudo se sucede". Em outras palavras, a apreensão que é feita da pintura se dá de uma só vez, ainda que se possa, como ele diz, "errar pelo quadro, ater-se a uma tal cor, observar de alto a baixo", o quadro em si é apreendido como um todo. Contrariamente, na música, escutamos o encadeamento das frases musicais, sem a possibilidade de retornar a um ou outro trecho.

${ }^{12}$ Aliás, deve-se destacar que esta preocupação já se insinua em 1907, ano em que Apollinaire publica um texto sobre Henri Matisse, no qual observa que a finalidade do pintor se dirige "à expressão plástica" (1991, p. 100-103)..
} 
Entende-se que não se trata, neste caso, de aplicação de regras, geométricas ou gramaticais, mas sim do modo como os artistas, pintores ou escritores, fazem uso - ou não - destas regras em seus processos de produção artística. Neste sentido, é bastante ilustrativa a distinção proposta pelo poeta, segundo a qual os "jovens pintores" já não se limitariam às três dimensões da geometria euclideana, como seus predecessores, e, em consequência disso, teriam sido levados, como escreve Apollinaire, "a se preocupar das novas medidas de extensão que na linguagem dos ateliers modernos designamos resumidamente pelo termo de quarta dimensão" (1912a, p.90).

Ainda que o poeta não deixe muito claro o que entende pela designação quarta dimensão, é possível conjecturar que a expressão equivalha a um conceito por meio do qual ele pretenda desenvolver, ou meramente reforçar a ideia de "pintura pura" anteriormente exposta. Sabe-se que essa discussão será retomada por Apollinaire em seu Les Peintres Cubistes. Méditations Esthétiques, único livro que reúne parte de sua reflexão estética feita no período, e que nas notas feitas a este texto pelos organizadores de suas obras completas, estes últimos consideram a quarta dimensão um "lugarcomum" da época (1991, p. 1512). Além disso, acrescente-se que Mauryce Raynal (1952, p. 26), que também foi um colaborador das Soirées ${ }^{13}$, relata que por volta destes anos pintores e escritores, especialmente os que circulavam pelo atelier de Picasso no Montmartre, o Bateau-Lavoir, se interessavam por tudo, incluindo as matemáticas. Segundo Raynal, não de forma dogmática, falavase sobre a quarta dimensão mas como "fonte de exemplo de lirismo, de invenção ou de audácia não conformista" (1952, p. 26), e não com pretensões teóricas.

Segundo Apollinaire a quarta dimensão seria a responsável por figurar a imensidão do espaço, "se eternizando em todas as direções a um momento determinado"; a quarta dimensão, considera o poeta, "é o espaço mesmo, a dimensão do infinito", sendo ela, ainda, a que "dota de plasticidade os objetos", lhes conferindo as proporções adequadas na constituição da obra de arte.

Especulações em torno do termo, ou mais especificamente do emprego que dele faz Apollinaire, permitiriam supô-lo como correspondente a uma outra etapa do trabalho artístico. Se, como se viu, a ideia de "pintura pura" atrela-se ao trabalho com as partes que compõem a pintura de maneira orgânica, ou seja, o que a especifica enquanto pintura mesma, a ideia de quarta dimensão poderia estar sendo empregada por Apollinaire como alusiva a este mesmo trabalho, ao processo em si. Em certo sentido, bastante restrito, seria uma forma de referir o próprio fazer plástico que, ausente das três dimensões figuradas no quadro, é o métier de todo artista. De um modo mais amplo, a ideia de quarta dimensão, tal como é exposta por Apollinaire, sugere a articulação entre o visto, o que se figura no quadro - "o espaço mesmo", como ele escreve - e o suposto ou o sugerido, o que não se figura na tela - "a dimensão do infinito", da qual se pode inferir inumeráveis possibilidades.

Ora, se a quarta dimensão é a que, como escreve Apollinaire, "dota de plasticidade os objetos", parece plausível considerá-la como alusiva ao processo artístico em si mesmo. Só para lembrar, o que talvez sirva de apoio ao que aqui se está propondo, um pintor contemporâneo e amigo de Apollinaire, Robert Delaunay, falará, ao se referir a seu métier, sobre o uso - destaco - da cor como forma, plástica, é claro. Em seu trabalho, o pintor de Fenêtres Simultanées sur la Ville, Disques, Hommage à Blériot, entre outros quadros em que a ênfase de seu procedimento está no uso que faz da cor, é exatamente este tipo de uso, ou em outros termos, o processo mesmo, que confere "plasticidade ao objeto", para aproveitar a sugestão de Apollinaire. Inclusive, ao escrever sobre Robert Delaunay o poeta visará sempre o seu métier, destacando o procedimento do pintor, o que não é visto pelo espectador mas sobre o qual Apollinaire, que acompanha o trabalho de Delaunay em seu atelier, pode escrever.

\footnotetext{
${ }^{13}$ Raynal inaugura e mantém uma coluna dedicada à crítica cinematográfica, um caso singular, talvez, para a época. Sabese do interesse que Apollinaire tinha pelo cinema, o que é evidenciado por um artigo publicado já em 1905 sobre o Cinematógrafo, no periódico Le Journal de Salonique.
} 
A propósito, não parece fortuito o fato de que no $\mathrm{n}^{\circ} 11$ de Soirées, de dezembro de 1912, Apollinaire decida publicar trechos de notas redigidas pelo próprio Delaunay ${ }^{14}$. Em "Réalité. Peinture Pure"(1912b), é possível localizar diversas passagens em que Robert Delaunay enfatiza sua preocupação com o processo que ele, atualizando e incrementando pesquisas efetuadas, sobretudo, por Georges Seurat e Paul Signac no século XIX, nomeará de "contraste simultâneo de cores". Esta noção de contraste simultâneo que apenas se entrevê nos trechos de notas de Delaunay é duplamente importante para Apollinaire pois ela retém a atenção do poeta não só sobre sua aplicação à pintura mas também, como se verá mais adiante, na poesia. No n 18 de Soirées de Paris Apollinaire comenta a exposição de Delaunay realizada na galeria Der Sturm em Berlim no ano de 1913, dando destaque para as obras "simultaneístas" do pintor, das quais as mencionadas acima são um exemplo. Não se deve esquecer também que para esta mesma exposição é Apollinaire quem redige o prefácio do catálogo, um poema, intitulado Les Fenêtres, que apresenta de um modo sintético e poético o procedimento de Delaunay e que ele considerará como um de seus principais poemas - além de também se referir a este mesmo como sendo um de seus primeiros poemas "simultâneos" (Cf. APOLLINAIRE, 1952, p. XXX).

Note-se no entanto que a chamada "Pintura Pura" não é uma invenção de Apollinaire. Assim como a ideia de quarta dimensão, a que se faz em torno da pintura pura circula na época, nem sempre com o mesmo termo designativo, como evidenciam escritos de outros críticos ${ }^{15}$ contemporâneos do poeta. Além disso, o próprio Apollinaire reconhece a "evolução" da chamada pintura pura em um texto sobre o Salão dos Indenpendentes publicado em 25 de março de 1913. Considerando como termo equivalente a pintura pura o termo orfismo, o qual ele propõe para designar a pintura de Delaunay, escreve o poeta que "Esta tendência não foi uma invenção súbita; ela é a evolução lenta e lógica do impressionismo, do divisionismo, da escola dos fauves e do cubismo" (APOLLINAIRE, 1965, p. 547-548).

Em linhas gerais, a atuação de Apollinaire no que se considera a primeira fase das Soirées de Paris seria pautada, de um lado, pela defesa da pintura nova e, de outro, pela publicação de alguns de seus poemas. A proposta de divisão em duas fases é feita, entre outros, por Noëmi Blumenkranz-Onimus, que em seu referido artigo propõe que é possível considerar como a primeira fase de Soirées a que vai de seu primeiro número, publicado em fevereiro de 1912, até o número 17, de junho de 1913, período em que a revista foi dirigida por André Billy. O próprio Billy (1966, p. 82-85) é quem relata que as dificuldades financeiras, associadas a outras, como a de encontrar novos colaboradores interessados em tocar o projeto, levou-o a renunciar da direção da revista. Billy conta que por essa época se encontrara ao acaso com Apollinaire e que lhe transmitira seu desejo de se afastar da publicação. Nesta ocasião, Apollinaire se oferecera para assumir a direção da revista, garantindo a Billy que o faria com o mesmo empenho com o qual se aplicara ele à função até então. Apollinaire se informa a respeito de todos os problemas pelos quais passava a revista e sai em busca de um novo financiador que, movido pelos mesmos interesses que os colaboradores da publicação, se dispusesse a investir o capital necessário para a continuidade das atividades des Soirées de Paris.

O último número sob a direção de Billy é publicado em junho de 1913 e o número seguinte, sob nova direção, apenas em novembro de 1913. Neste ínterim Apollinaire, possivelmente já decidido sobre o novo financiador da publicação, procura por duas figuras de reputação nos meios artísticos e nas rodas intelectuais parisienses: Serguei Nikolaievitch Jastrebzov, ou Serge Férat, e a baronesa Hélène d'Ettingen: ambos russos de nascimento, ambos pintores, ambos interessados por literatura e pintura e, o que era o principal, ambos muito ricos, segundo escrevem. É assim que, deste encontro, sob o

\footnotetext{
${ }^{14}$ Estas notas foram reunidas, anotadas e publicadas postumamente pelo historiador Pierre Francastel em $D u$ Cubisme à l'Art Abstrait. Paris: S.E.V.P.E.N. Bibliotèque Générale de l"école Pratique des Hautes-Études, 1957.

${ }^{15}$ A circulação de ideias semelhantes às de Apollinaire em torno da pintura da época é posta em destaque por John Golding em seu estudo sobre o cubismo. No primeiro capítulo o autor expõe, às vezes recorrendo à citações, que críticos como André Warnod, Olivier Hourcade ou Allard, também defendiam uma pintura que se preocupasse com o que lhe fosse mais específico, o que caracteriza a pintura pura tal como tratada por Apollinaire (Cf. GOLDING, 1965)
}

R. Inter. Interdisc. Art\&Sensorium, Curitiba, v.8, n.1, p. 271 - 281 Jan.- Jun. 2021 
pseudônimo de "Jean Cerusse" - corruptela de "Ces Russes", "estes russos" - os dois, que eram primos, assinariam a direção da revista ao lado de Apollinaire. Mais com Serge que com Hélène, Apollinaire trata, em cartas, sobre a reativação das atividades de Soirées de Paris. Assim, lê-se em carta enviada pelo pintor, e um dos financiadores da nova fase da revista, ao poeta:

\begin{abstract}
Não entendi em sua carta se suas preferências são pela compra de Soirées de Paris ou pela criação de uma nova revista e, em caso de compra se você deseja manter as mesmas dimensões ou apenas usar o mesmo título. Será necessário também saber o preço da impressão. Naturalmente os 18 meses de existência de uma revista não são desprezíveis mas para que ela mude radicalmente suas tendências [destaque meu] poderíamos manter alguns dos assinantes. Faça como julgar melhor e em caso de desejar manter as Soirées de Paris proponha à Billy os 200 francos. (APOLLINAIRE, 2009, p. 554-555)
\end{abstract}

Ao ler as correspondências trocadas entre Apollinaire e Férat, entende-se que se o poeta, como dizia Billy, pouco se interessava pelos detalhes da publicação, nesta segunda fase da revista assumirá praticamente toda a responsabilidade sobre os novos números de Soirées de Paris. Em nota a uma das cartas enviadas por Apollinaire a Férat, na qual o poeta menciona a necessidade de que Férat se ocupe do "tratado" relativo à revista, os organizadores do volume das correspondências esclarecem que se trata da reestruturação das finanças da publicação e de sua nova orientação editorial "para relançar a revista em uma direção mais radicalmente moderna" (APOLLINAIRE, 2009, p. 587). Em outras passagens desta mesma carta, Apollinaire requisita a Férat providenciar fotos do Ubu Roi, de Alfred Jarry, o envio de poemas, a preparação de provas, entre outras demandas necessárias à elaboração de um novo número de Soirées.

Em cartas posteriores, já estando a revista novamente em atividade, Apollinaire trata dos clichês de obras que serão reproduzidas na Soirées, com as de Braque, Matisse, Picabia, o que serve de indício de que a responsabilidade pelo novo aspecto visual da revista era encargo de Apollinaire. Aliás, esta será uma das marcas que o poeta deixará impressa na publicação, uma vez que é somente após assumir a sua direção que as Soirées começará a reproduzir obras de artistas que anteriormente eram divulgados e defendidos apenas em textos, sempre assinados pelo poeta.

Neste sentido, é de se destacar que, já no primeiro número publicado sob sua direção, o 18 , de novembro de 1913, Apollinaire faz com que sejam reproduzidas imagens de obras de Picasso: cinco naturezas-mortas do pintor catalão sendo uma delas utilizada na capa da publicação. No número seguinte, são reproduzidas obras de Marie Laurencin, La Jeune Fille au Piano, Henri Matisse, Portrait, Jean Metzinger, En Canot, Albert Gleizes, Les Bateaux de Pêche, todas elas expostas no Salão de Outono daquele ano de 1913, como indicam as legendas que as acompanham. No número 19 anuncia-se que o seguinte, o número 20, será dedicado a Henri Rousseau, o Douanier, morto três anos antes. Neste número, além de inúmeras reproduções de suas obras - entre elas a célebre La Muse Inspirant le Poète, um retrato de Apollinaire - textos e poemas homenageiam aquele que era considerado o mestre de $\operatorname{todos}^{16}$. Esta mesma preocupação com a divulgação das obras de pintores que atuavam em Paris naqueles anos será vista em todos os números sequentes, nos quais se pode localizar reproduções de obras de André Derain ( $\left.\mathrm{N}^{\mathrm{o}} 21\right)$, Francis Picabia ( $\left.\mathrm{N}^{\mathrm{o}} 22\right)$, Georges Braque $\left(\mathrm{N}^{\mathrm{o}} 23\right)$, Henri Matisse ( $\left.\mathrm{N}^{\circ} 24\right)$ entre outras.

\footnotetext{
${ }^{16}$ A importância de Rousseau para os pintores desta geração é destacada por muitos comentadores da pintura do período, como o já citado John Golding. Além dele, a importância de Rousseau é enfatizada por André Salmon, que escreve no número 20 de Soirées sobre o banquete oferecido a este artista no atelier de Picasso, o Bateau Lavoir. O mesmo autor lembra do episódio em seu livro de memórias, Souvenirs sans Fin. Outros a darem destaque a Rousseau são, Maurice Raynal, em "Le Montmartre au Temps du Bateau Lavoir", Fernande Olivier, em Picasso et ses Amis e, ainda, Jeanine Warnod em Le Bateau Lavoir.
} 


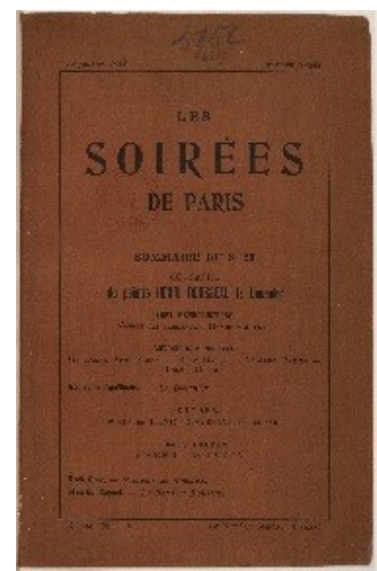

Figura 4 - Capa do número 20 de Les Soirées de Paris consagrado ao pintor Henri Rousseau 15 de janeiro de 1914

Fonte: Gallica - Bibliotèque Nationale de France

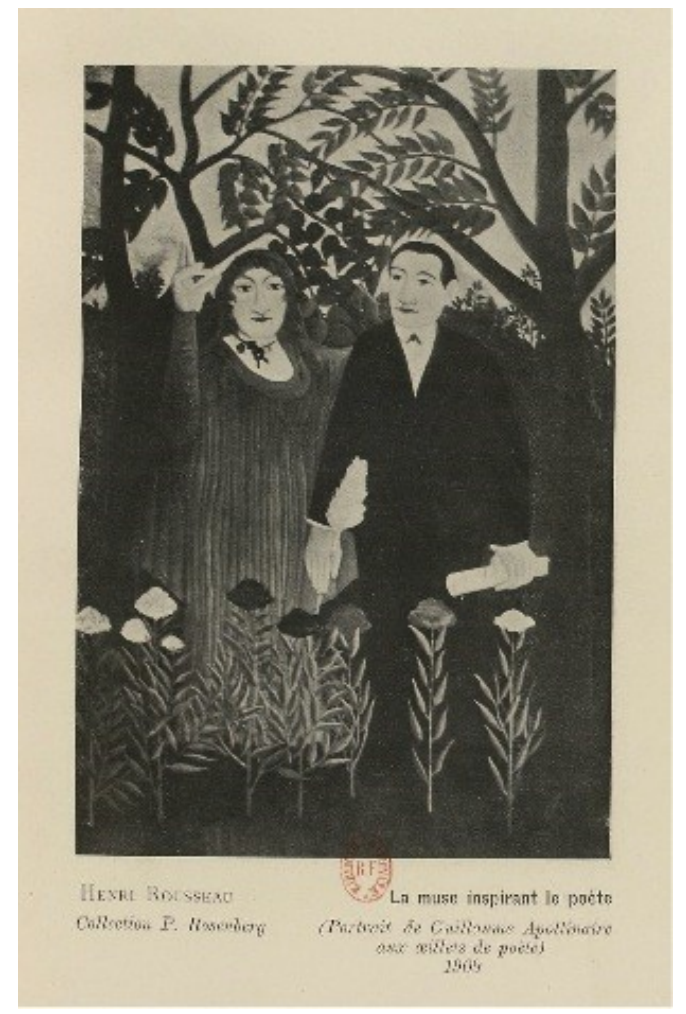

Figura 6 - La Muse Inspirant le Poète (Portrait de Guillaume Apollinaire aux œillets de poète 1909) Fonte: Gallica - Bibliotèque Nationale de France

Conforme ao que observam alguns autores, a iniciativa, audaciosa para a época, de Apollinaire de reproduzir obras destes artistas na revista rendeu à publicação o pedido de cancelamento de diversos assinantes ${ }^{17}$ o que, ao que tudo indica, não preocupava os financiadores, Serge Férat e Hélène d'Ettingen, que confiavam toda a nova vida da revista a Apollinaire. Como escreve Alexandra Parigoris, por exemplo, após Apollinaire as Soirées de Paris "tornam-se um evento artístico mensal, apresentando a arte contemporânea como um produto da moda, digna de interesse de colecionadores

\footnotetext{
${ }^{17}$ Segundo André Parinaud, 40 assinantes cancelam a assinatura da revista logo no primeiro número publicado sob a direção de Apollinaire. Conforme observa o mesmo autor, esta cifra evidencia o "verdadeiro nível cultural e as opções do público, surpresos com a audácia da nova forma" (Cf. PARINAUD, 1994, p. 359).
}

R. Inter. Interdisc. Art\&Sensorium, Curitiba, v.8, n.1, p. 271 - 281 Jan.- Jun. 2021 
do "beau-monde" parisiense e, ainda mais, internacional" (1988 pp. 61-74). Noëmi BlumenkranzOnimus (1971, p. 1097), que também escreve sobre a revista, afirma que o desígnio de Apollinaire era o de assegurar o seu sucesso divulgando e defendendo a arte moderna, pois as Soirées de Paris, na visão do poeta, deveria ser a "mais moderna das revistas modernas atuais" e reproduzir, por consequência, as obras de arte mais modernas feitas àquela época.

Pode-se ter uma ideia do que representava a exposição das obras destes artistas naqueles anos de 1913 a partir da simples comparação com as obras que eram reproduzidas em outras revistas da época. Em L'Essor, para lembrar uma das revistas já destacadas, divulgava-se artistas como Antoine Calbet, Octave Denis Guillonet, Mac Cameron, M. Lappara, P. A. Laures, Henri Morisset, Auguste Roubille, André Devambez, nomes, dispensável dizer, pouquíssimo conhecidos nos dias de hoje e, quiçá, em sua própria época.

As polêmicas geradas a partir das escolhas de Apollinaire não se deram apenas acerca do novo aspecto visual da revista, como no caso das comentadas reproduções. Como dito no início, o primeiro texto de Apollinaire publicado nas Soirées provocou a indignação de René Dalize, um dos sóciosfundadores da revista. De modo mais amplo, as polêmicas travadas pelo poeta extravasaram o círculo dos colaboradores, assinantes e leitores da revista. É o que se nota em relação ao artigo publicado no número 25 de Soirées, "Simultanisme Librettisme", em que Apollinaire questiona a origem da proposição da ideia de "simultaneísmo" aplicada à poesia. Como se sabe, Henri-Martin Barzun, diretor da revista Poème et Drame, com a qual Apollinaire havia colaborado, propõe no Manifeste sur le Simultaneísme Poétique ter sido ele o idealizador do conceito, e é contra esta posição, enfatizada em artigos publicados por Barzun, que Apollinaire publica, entre outros textos, o que se localiza no referido número das Soirées ${ }^{18}$. Além de Barzun, também entram na disputa poetas e artistas ligados ao futurismo, como Marinetti e Boccioni, Blaise Cendrars, que no ano de 1913 havia publicado, em parceria com Sonia Delaunay, a sua Prose du Transsibérien et de la Petite Jeanne de France e, ainda, o pintor Robert Delaunay, que se autodesignava "le simultané" e que havia apresentado pinturas "simultâneas" na exposição de Berlim para a qual Apollinaire redigira o poemaprefácio Les Fenêtres. A polêmica se desenvolve ao longo de mais de um ano e marca como tantas outras, a passagem de Apollinaire à frente de uma das mais importantes revistas de vanguarda artística publicadas nos anos que precedem a Primeira guerra mundial. Por meio dela, Apollinaire não apenas fixou o seu nome no debate artístico do período, mas também, e principalmente, levou a cabo o projeto de sua vida: a defesa da pintura, das letras e das artes modernas.

\section{Referências Bibliográficas}

ADÉMA, Pierre-Marcel. Apollinaire le Mal-Aimé. Paris: Libraire Plon, 1952.

APOLlinAIRE, Guillaume. Du Sujet dans la Peinture Moderne. Les Soirées de Paris, nº 1, p. 1-4, février 1912.

APOLLINAIRE, Guillaume. Guillaume Apollinaire. Correspondance avec les artistes - 1903-1918. Paris: Éditions Gallimard, 2009.

APOLLINAIRE, Guillaume. La Peinture Nouvelle, Notes d'Art. Les Soirées de Paris, nº 3, p. 89-92, avril 1912a.

APOLLINAIRE, Guillaume. Euvres en prose complètes, T. II. Paris: Gallimard, 1991

\footnotetext{
${ }^{18}$ Além do texto publicado nas Soirées de Paris, Apollinaire publica, no Paris-Journal, outros artigos nos quais dicute o mesmo assunto. Em 29 de junho de 1914, "À Propos de la Poésie Nouvelle"; em 3 de julho de 1914, "À Propos de l'Art Orphique. Le Mot de la Fin", e, em 11 de julho do mesmo ano, "Point Final".
} 
APOLLINAIRE, Guillaume. Réalité. Peinture Pure. Les soirées de Paris, nº 11, p. 348-349, decémbre $1912 b$.

APOLLINAIRE, Guillaume. Salon d'Automne. Les Soirées de Paris, nº 19, p. 46-49, décembre 1913. APOLLINAIRE, Guillaume. Tendre comme le Souvenir. Paris: Gallimard, 1952.

BILLY, André. Avec Apollinaire. Souvenirs Inédits. Paris-Genève: La Palatine, 1966.

BILLY, André. L'Époque Contemporaine, 1905-1930. Paris: Tallandier, 1956.

BLUMENKRANZ-ONIMUS, Noëmi. "Les Soirées de Paris ou le mythe du moderne". In: BRIONGUERRY, Lilianne (org.). Année 1913: les formes esthétiques de l'ouvre d'art à la veille de la première guerre mondiale. Paris: Klincksieck, 1971. Vol. 1. pp. 1097-1104.

DELAUNAY, Robert. Du Cubisme à l'Art Abstrait. Paris: S.E.V.P.E.N. Bibliotèque Générale de l"école Pratique des Hautes-Études, 1957.

GOLDING, John. Le Cubisme. Paris: Éditions René Juillard; Le Livre de Poche, 1965

PARIGORIS, Alexandra. Les Constructions Cubistes dans Les Soirées de Paris. Apollinaire, Picasso et les clichês Kahnweiler. La Revue de l'Art, no 82, p. 61-74, 1988.

PARINAUD, André. Apollinaire 1880-1918. Biographie. Éditions Jean-Claude Lattès, 1994.

RAYNAL, Raynal. Montmartre au Temps du Bateau-Lavoir. Médecine de France, no 35, p. 17-30, 1952.

VENTURI, L. Histoire de la Critique d'Art. Paris: Flammarion, 1969. 